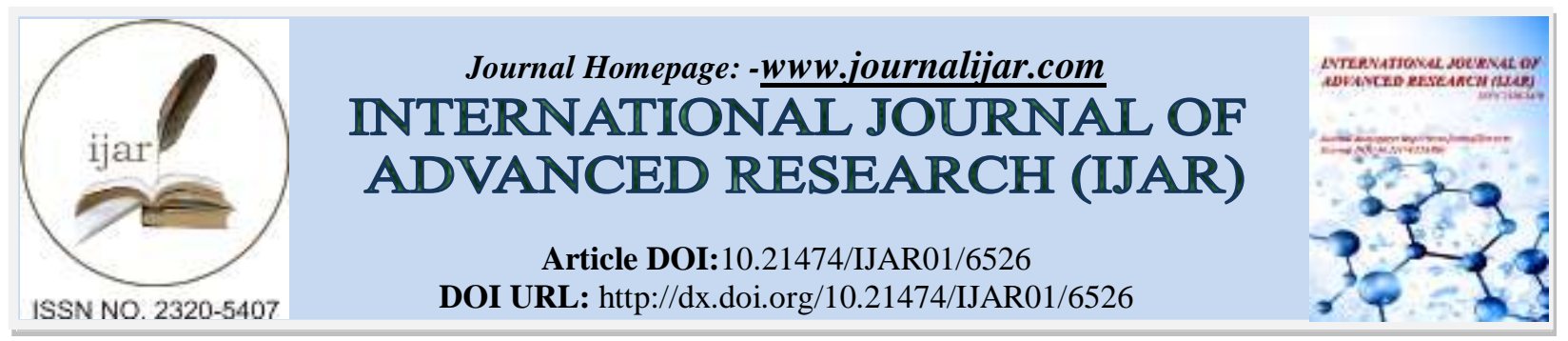

RESEARCH ARTICLE

\title{
TB-PCR, UTILITY IN PRESENT SCENARIO - STUDY FROM TERTIARY CARE CENTER IN NORTHERN INDIA.
}

Virendra Atam, Arpit Gupta, Gyan Ranjan Nayak, Prachi Daga and Isha Atam.

\section{Manuscript Info}

-.........................

Manuscript History

Received: 13 December 2017

Final Accepted: 15 January 2018

Published: February 2018

\section{Abstract}

Copy Right, IJAR, 2018,. All rights reserved.

\section{Introduction:-}

TBM is one of the most common causes of sub-acute lymphocytic meningitis in the developing countries. In developing countries, TB meningitis is still a disease of childhood with the high incidence in the first three years of life (Tandon PN, Brattier R, Handbook of clinical neurology, Donald PR). Tuberculous meningitis (TBM) can occur as the sole manifestation of Tuberculosis. ${ }^{(1-3)}$ Delays in seeking medical care, diagnosis, and initiation of treatment are contributing factors to the high mortality and morbidity, especially in resource-limited regions. When diagnosed promptly, TBM can be cured with supervised medication administration and supportive care. Even after many years of experience with the disease, the definitive diagnosis of TBM remains a problem. Early diagnosis and treatment of TBM is necessary because in the untreated patients the mortality is $100 \%$ in 5 to 8 weeks (Molavi and Le Frock 1985). The definitive diagnosis can be done by isolating the tubercle bacilli from the CSF, the conventional diagnostic modalities like microscopy and culture lack sensitivity and are time-consuming and most often culture is negative in paucibacillary conditions. The nucleic acid amplification technique (NAA), notably the polymerase chain reaction (PCR) has revolutionized the investigative microbiology by facilitating direct detection and identification of infectious agent in the clinical samples in a very short time. Sensitivities vary from $33 \%$ to $90 \%$, specificities from $88 \%$ to $100 \%$.

For diagnosis of $M$. tuberculosis, a large number of different sequences of Mycobacterium genome have been targeted. Most of the studies have targeted IS6110 sequence of M. tuberculosis; however, absence or presence of only a few copies of this sequence has been reported in some isolates. Studies from India have also reported that IS6110 is missing in $40 \%$ of North Indian population. ${ }^{(4)}$ There is need to use more than one target specific for $M$. tuberculosis complex to increase the sensitivity and specificity of the test. To overcome this limitation, multiplex PCR for diagnosis of MTB complex using IS6110, MPB64, and protein b was developed by Sharma et al, which had a sensitivity of $94.4 \%$ in culture/smear-positive cases of tubercular meningitis and $85 \%$ in clinically diagnosed but culture negative cases of tubercular meningitis. ${ }^{(5)}$

The PCR was positive in $75 \%$ of those clinically adjudged to have highly probable or probable TBM, and whom improved on treatment. Future studies need to use universal and evaluated clinical diagnostic criteria. TB PCR identifies a minimum of 10-1000 organisms.

Transcription Mediated Amplification(TMA) and nucleic acid amplification(NAA):-

It uses chemical, rather than biological amplification to produce nucleic acid, so that within a few hours these tests 
distinguish between M tuberculosis complex and NTM in an AFB positive specimen.

\section{Cartridge-based NAA: -}

The second generation NAAT based TB diagnostic offers very high sensitivity approaching the liquid culture the current gold standard. It also provides information on drug sensitivity to rifampicin.

\section{Gene Xpert MTB/RIF: -}

It detects DNA sequences specific to M tuberculosis and rifampicin resistance by PCR. It is a simple and rapid type of NAAT. The process identifies all the clinically relevant rifampicin resistance inducing mutation in the rpoB gene in the Mycobacterium tuberculosis genome in a real-time format using fluorescent probes called molecular beacons. Results are obtained within minutes.

So, PCR could be used in detection of $M$ tuberculosis in pulmonary specimens but is not yet fully evaluated for the diagnosis of TBM. ${ }^{(6)}$

This study was done with an aim to establish the role of TB-PCR, in the diagnosis of tuberculous meningitis.

\section{Materials and Methods: -}

This prospective study was done in Department of Medicine, and Department of Neurology over the one-year duration. The subjects were comprised of the patients above 10 years of age who got admitted with clinical picture commensurate with Meningitis were assessed on Thwarts Criteria and those found to be likely cases of T.B.M, as per the criteria were included in the study.

Exclusion criteria:

1. Patients/attendants refusing consent.

2. Patients not fulfilling the Thwaites criteria.

3. Brain abscess

4. Head trauma

Table 1:-Thwaites Criteria

\begin{tabular}{|l|l|l|}
\hline Parameters & $>=35$ years & DI \\
\hline Age & $<35$ years & 2 \\
& $>=15000$ & 0 \\
\hline Blood WBC, $10^{3} / \mathrm{ml}$ & $<15000$ & 4 \\
& $>=6$ days & 0 \\
\hline CSF total WBC, $10^{3} / \mathrm{ml}$ & $<6$ days & -5 \\
& $>=900$ & 0 \\
\hline CSF \% neutrophils & $<900$ & 3 \\
& $>=75 \%$ & 0 \\
\hline DI $>$ 4: TBM & $<75 \%$ & 4 \\
DI 1-4 : other bacterial meningitis & & 0 \\
\hline
\end{tabular}




\section{PATEINTS WITH CLINICAL FEATURES OF TUBERCULOUS MENINGITIS}

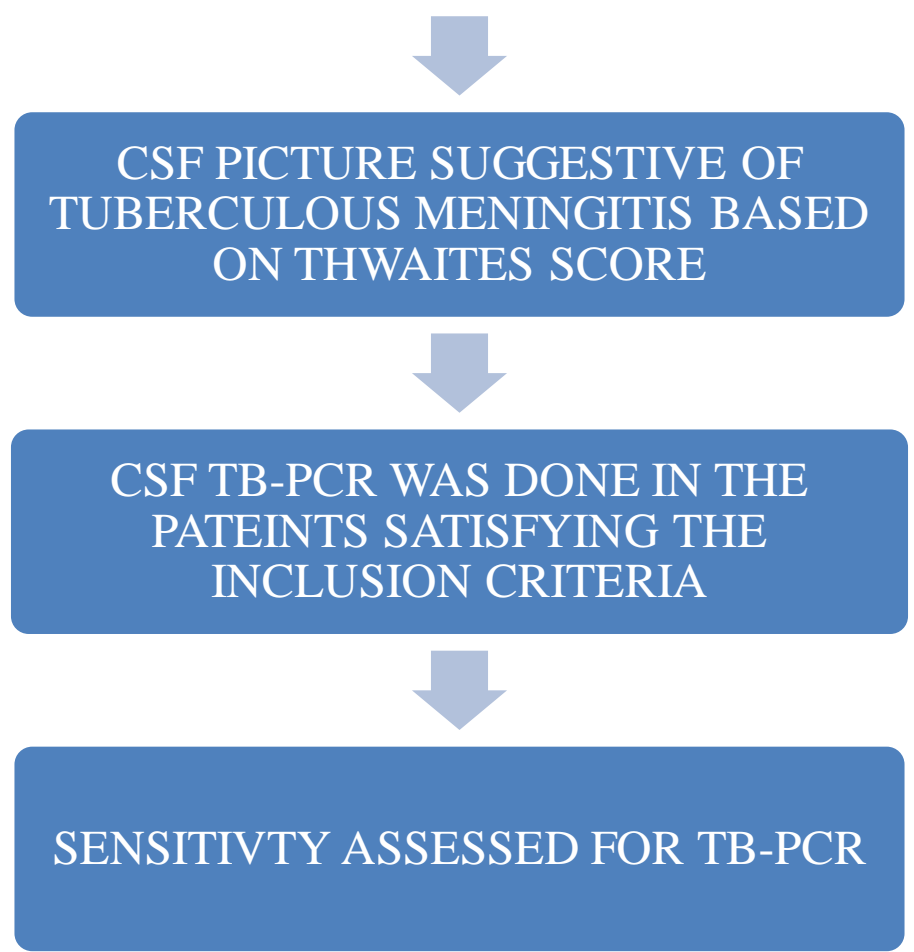

Results:-

Table 2:-Sensitivity Of Tb Pcr For Thwaites Score $\leq 4$ (N=99)

\begin{tabular}{|c|c|c|c|}
\hline \multirow{2}{*}{ PCR } & \multicolumn{2}{|c|}{ Thwaites score $\leq \mathbf{4}$} & \multirow{2}{*}{ Total } \\
\cline { 2 - 4 } & $\mathbf{4}$ units & $\mathbf{> 4}$ units & 42 \\
\hline Positive & 42 & 0 & 57 \\
\hline Negative & 57 & 0 & 99 \\
\hline & 99 & 0 & \\
\hline
\end{tabular}

Taking PCR positivity as the diagnostic test and evaluating its efficacy against Thwaites score $\leq 4$, out of 99 cases of TBM, 42 were found to be true positive and 57 were false negative. There was negative case included in the assessment, hence no true negative or false positivity could be assessed. In this limited situation, the sensitivity and accuracy was $42.4 \%$.

\section{Discussion:-}

TBM is an important cause of chronic meningitis in our country with significant morbidity and mortality and early diagnosis and treatment are essential to decrease the adverse outcomes. Despite years of experience, it is over and under-diagnosed. This study was conducted and analyzed as a prospective study at the Department of Internal Medicine, KGMU, Lucknow. The subjects of the study were patients who were admitted with the clinical syndrome of meningitis and were diagnosed to be suffering from TBM based on the THWAITES CRITERIA. Taking PCR positivity as the diagnostic test out of 99 cases of TBM diagnosed by Thwaites score, $42.42 \%(n=42)$ were found to be positive. 


\section{Conclusion:-}

Taking PCR positivity as the diagnostic test, out of 99 cases of TBM diagnosed by Thwaites score only $42.42 \%$ $(n=42)$ were found to be true positive, hence it is not a good test for the diagnosis of Tuberculous meningitis.

\section{References:-}

1. Thwaites G, Fisher M, Hemingway C, Scott G, Solomon T, Innes J. British Infection Society guidelines for the diagnosis and treatment of tuberculosis of the central nervous system in adults and children. $\mathbf{J}$ Infect2009;59:167-187 [PubMed]

2. Chakraborty AK. Estimating mortality from tuberculous meningitis in a community: Use of available epidemiological parmeters in the Indian context. Ind J Tub 2000;47:9-12

3. Nelson C, Zunt JR. Tuberculosis of the central nervous system in immunocompromised patients: HIV Infection and solid organ transplant recipients. Clin Infect Dis 2011;53:915-926 [PMC free article][PubMed]

4. Chauhan DS, Sharma VD, Prashar D, Chauhan A, Singh HB, et al. Molecular typing of mycobacterial tuberculosis isolates from different parts of India based on IS6110 element polymorphism using RFLP analysis. Indian J Med Res 2007;125:577-581

5. Sharma K, Sharma A, Ray P, Sharma SK, Modi M, Prabhakar S, Varma S, Sharma M. Multiplex PCR for rapid diagnosis of tuberculous meningitis. J Neurol 2011;258:1781-1787.

6. Thwaites GE, Macmullen-Price J, Tran TH, et al. Serial MRI to determine the effect of dexamethasone on the cerebral pathology of tuberculous meningitis: an observational study. Lancet Neurol 2007;6:230-6. 